\title{
Evaluation of a Colorectal Carcinoma Screening Program in Kota Setar and Kuala Muda Districts, Malaysia
}

\author{
Muhammad Radzi Abu Hassan', Tan Wei Leong ${ }^{1 *}$, Delarina Frimawati Othman \\ Andu $^{1}$, Habshoh Hat ${ }^{2}$, Nik Raihan Nik Mustapha ${ }^{3}$
}

\begin{abstract}
Background: A colorectal cancer screening program was piloted in two districts of Kedah in 2013. There is scarcity of information on colorectal cancer screening in Malaysia. Objective: Thus, this research was conducted to evaluate the colorectal cancer screening program in the districts to provide insights intop its efficacy. Materials and Methods: A cross sectional study was conducted using data on the colorectal cancer screening program in 2013 involving Kota Setar and Kuala Muda districts in Malaysia. We determined the response rate of immunochemical fecal occult blood test (iFOBT), colonoscopy compliance, and detection rates of neoplasia and carcinoma. We also compared the response of FOBT by demographic background. Results: The response rate of FOBT for first iFOBT screening was $94.7 \%$ while the second iFOBT screening was $90.7 \%$. Participants from Kuala Muda district were 27 times more likely to default while Indians had a 3 times higher risk of default compared to Malays. The colonoscopy compliance was suboptimal among those with positive iFOBT. The most common finding from colonoscopy was hemorrhoids, followed by tubular adenoma. Detection rate of carcinoma and neoplasia for our program was $1.2 \%$. Conclusions: In summary, the response rate of iFOBT was encouraging but the colonoscopy compliance was suboptimal which led to a considerably low detection rate.
\end{abstract}

Keywords: Colorectal cancer - screening - iFOBT - colonoscopy - compliance - Kedah - Malaysia

Asian Pac J Cancer Prev, 17 (2), 569-573

\section{Introduction}

Colorectal cancer accounted for $12.3 \%$ of total malignancy in 2007 and ranked as the second most common malignancy in Malaysia $(\mathrm{MOH}, 2007)$. Furthermore, colorectal cancer was also the second most common carcinoma in both male and female in 2007 (MOH, 2007). Colorectal tumours typically progress from normal mucosa into invasive cancer which may spread distantly to other organs. From previous studies, stage upon diagnosis has been an independent prognostic factor (Compton et al., 2000; O'Connell et al., 2004). Thus, diagnosing our patients at an early stage is crucial to reduce their mortality risk. To achieve this aim, colorectal cancer screening is a significant intervention as colorectal cancer screening can significantly reduce colorectal cancer mortality risk (Hardcastle et al., 1996; Kronborg et al., 1996; Hewitson et al., 2008).

Colorectal cancer screening had been widely recommended in gastroenterology guidelines in numerous countries (Cairns and Scholefield, 2002; Winawer et al., 2003; Cairns et al., 2010), though, its utilization is questionable. On top of that, non-use of colorectal cancer screening had been blamed for more than half of the mortality in United States (Meester et al., 2015). At the same time, combination of fecal occult blood test (FOBT) complemented with sigmoidoscopy or colonoscopy was found to be most cost effective strategy in colorectal cancer screening (Frazier et al., 2000). In Malaysia, the scarcity of published information on colorectal cancer screening prompted us to evaluate the current existing colorectal cancer screening in two districts of Kedah.

\section{Materials and Methods}

A cross sectional study was conducted to evaluate the pilot colorectal cancer screening program involving 2 districts in the state of Kedah, 2013. The study used secondary data collected from the colorectal cancer screening program whereby all patients underwent colorectal cancer screening in 2013 were included. The colorectal cancer screening was under the initiative of Ministry of Health involving Kota Setar and Kuala Muda districts in Kedah. Other than health clinics in both districts, Sultanah Bahiyah Hospital in Kota Setar district was also supplied with immunochemical fecal occult blood test kit (iFOBT) in 2013 to conduct colorectal cancer screening.

iFOBT was conducted using iFOBT kit whereby it would detect the presence of blood in the stool. 


\section{Muhammad Radzi Abu Hassan et al}

Participants must be 50 year-old or more, asymptomatic of colorectal malignancy, and were not on aspirin, warfarin or any blood thinning agent. A small container with buffer fluid equipped with a sampling stick for stool sampling was given to every patient for colorectal screening. Patient would be given instruction on sampling of stool and required to send the sample to health clinics immediately after sample collection. Laboratory assistant would then conduct the test using test kit. If the first iFOBT was positive, patients would be counseled and referred for colonoscopy. However, the patients would be subjected for second iFOBT if the first iFOBT was negative. The patients would be counseled and referred for colonoscopy if second iFOBT was positive. The flow of colorectal cancer screening is as in figure I.

In data analysis, proportions for positive for first and second iFOBT were calculated. On top of that, we also determine the dropout rate during the first iFOBT and second iFOBT. Colonoscopic findings were also tabulated. This study was registered with National Medical Research Register and approved by Medical Research Ethic Committee in Malaysia.

\section{Results}

From the data analysed, there was equal distribution for participants between both genders. On top of that, ethnicity composition in the program was similar with the ethnicity composition in both of the districts. Most of our patients enrolled were encountered at health clinics whereby health clinics functioned as the sentinels of health care system. When both of the districts were compared, Kota Setar districts had higher patient enrolment as compared to Kuala Muda distrirct.

Response rate and its association with demographic background

In total, there were 750 patients who enrolled in the screening program for year 2013 with response rate for first round of iFOBT was $94.7 \%$ with defaulter rate was $5.3 \%$. During the second round of iFOBT, response rate was $90.6 \%$ out of 663 patients enrolled while the defaulter rate was higher $9.4 \%$. Further analysis showed that patients from Kuala Muda were 27.54 times more likely to default from the program. On top of that, Indian ethnicity was also found to be 3 times higher to default as compared to Malay. However, there was no significant difference detected for Malay and Chinese.

\section{Positive iFOBT}

Among 750 tested patients in the first round of iFOBT, $47(4.8 \%)$ had positive iFOBT. In the second round of iFOBT, $25(3.7 \%)$ out of 663 had positive iFOBT which was slightly lower than the first round. In this study, none of the demographic characteristics was associated with positive iFOBT. When both rounds of colorectal cancer screening were summed up, the positive iFOBT was $9.6 \%$ of 750 enrolled patients.

\section{Colonoscopic compliance and findings}

All of the patients with positive iFOBT were referred

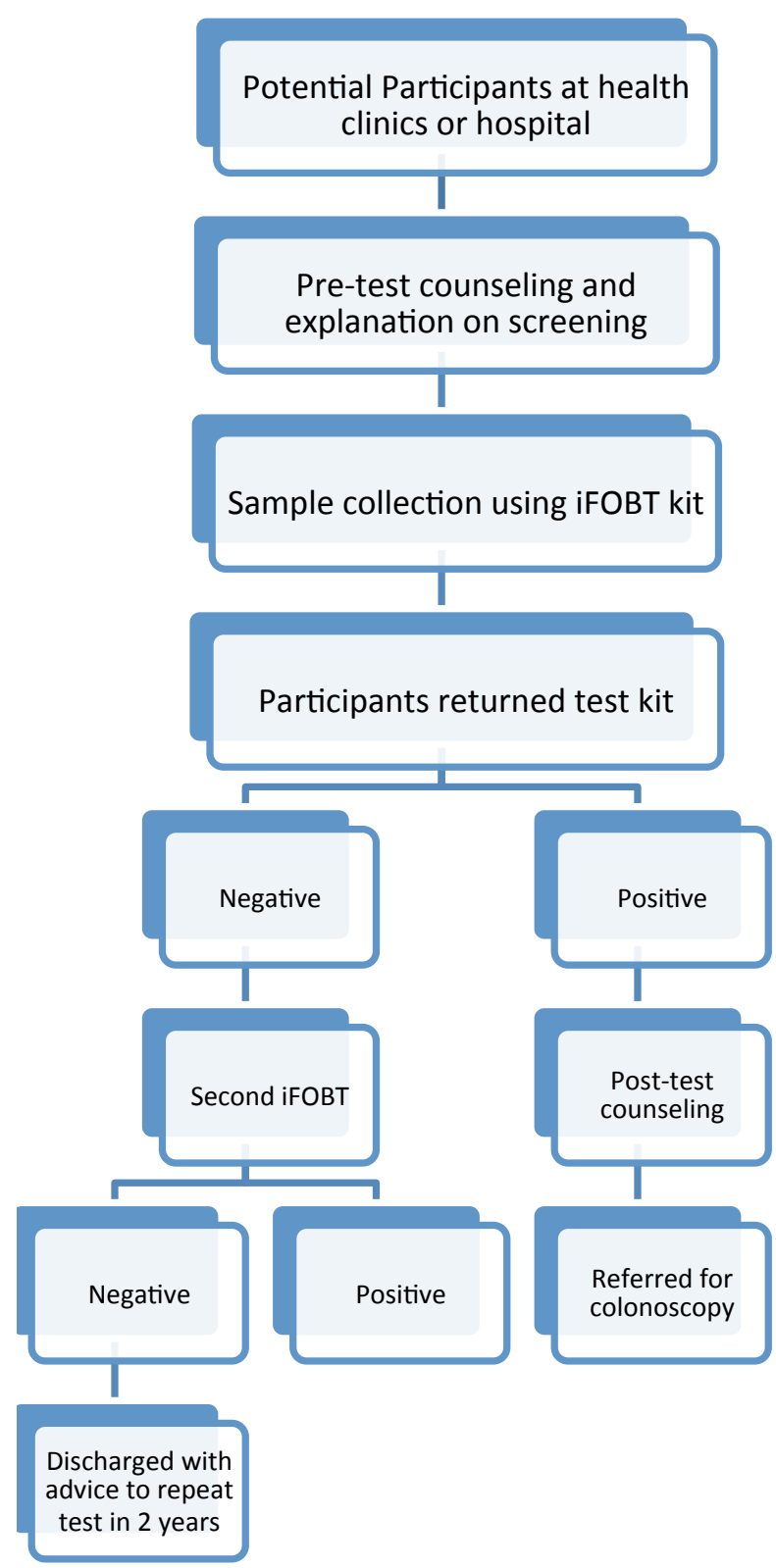

Figure 1. Process of Colorectal Cancer Screening

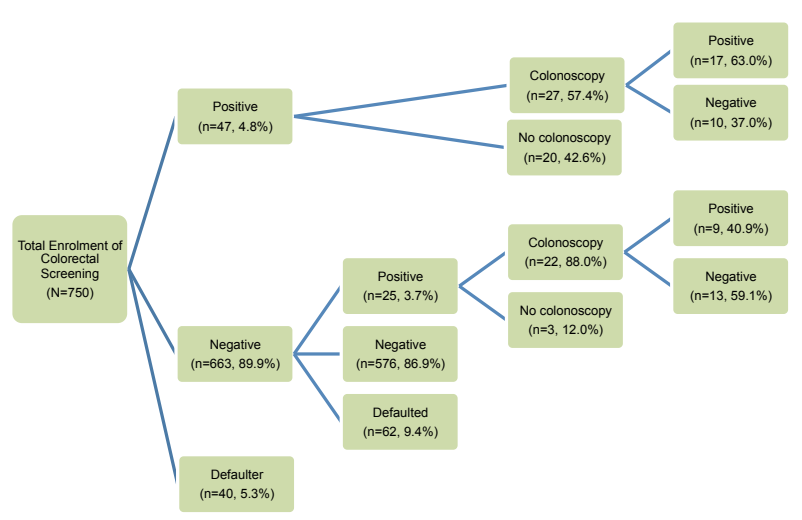

Figure 2. Detective Rate of Colorectal Carcinoma Screening Using iFOBT and Colonoscopy

for colonoscopy after counseling by medical practitioners. Compliance of colonoscopy in the screening program was $68.1 \%$ (49 out of 72 patients). Out of the 49 patients with colonoscopy, $26(53.1 \%)$ of our patients had positive 
Evaluation of a Colorectal Carcinoma Screening Program in Kota Setar and Kuala Muda Districts, Malaysia

Table 1. Demographic background of Respondents

\begin{tabular}{lcc}
\hline Demographic Characteristics & \multicolumn{2}{c}{ Overall } \\
\hline \multicolumn{1}{c}{ Gender } & $\mathrm{n}$ & $(\%)$ \\
Male & 358 & 47.7 \\
Female & 392 & 52.3 \\
TOTAL & 750 & 100 \\
Ethnic & & \\
$\quad$ Malay & 459 & 61.3 \\
$\quad$ Chinese & 238 & 31.7 \\
$\quad$ Indian & 49 & 6.5 \\
$\quad$ Other & 4 & 0.5 \\
$\quad$ TOTAL & 750 & 100 \\
Healthcare Facilities Used & & \\
$\quad$ Hospital & 204 & 27.2 \\
$\quad$ Health clinic & 546 & 72.8 \\
$\quad$ TOTAL & 750 & 100 \\
District & & \\
$\quad$ Kota Setar & 467 & 62.3 \\
$\quad$ Kuala Muda & 283 & 37.7 \\
$\quad$ TOTAL & 750 & 100 \\
\hline
\end{tabular}

Table 2. Comparison of Response for First iFOBT by Demographic Characteristics

\begin{tabular}{|c|c|c|c|}
\hline $\begin{array}{l}\text { Demographic } \\
\text { Characteristics }\end{array}$ & Adjusted OR & $95 \% \mathrm{CI}$ & P-value \\
\hline \multicolumn{4}{|l|}{ Gender } \\
\hline Female & 1 & Ref. & 0.843 \\
\hline Male & 0.94 & $(0.48 ; 1.82)$ & \\
\hline Ethnic & & & 0.016 \\
\hline Malay & 1 & Ref. & \\
\hline Chinese & 1.05 & $(0.46 ; 2.39)$ & 0.896 \\
\hline Indian & 3.47 & $(1.50 ; 3.16)$ & 0.003 \\
\hline \multicolumn{4}{|c|}{ Healthcare Facilities Used } \\
\hline Hospital & 1 & Ref. & 0.06 \\
\hline Health clinic & 0.13 & $(0.02 ; 1.09)$ & \\
\hline \multicolumn{4}{|l|}{ District } \\
\hline Kota Setar & 1 & Ref. & 0.001 \\
\hline Kuala Muda & 27.54 & $(3.69 ; 205.46)$ & \\
\hline
\end{tabular}

Table 3. Association Between Positive iFOBT and Demographic Background

\begin{tabular}{lrrr}
\hline $\begin{array}{l}\text { Demographic } \\
\text { Characteristics }\end{array}$ & $\begin{array}{r}\text { Positive } \\
\text { iFOBT }\end{array}$ & $\begin{array}{l}\text { Negative } \\
\text { iFOBT }\end{array}$ & P \\
\hline $\begin{array}{l}\text { Age group } \\
\text { 50 years or less }\end{array}$ & $5(13.9 \%)$ & $31(86.1 \%)$ & 0.4 \\
$\quad \begin{array}{l}\text { More than 50 } \\
\text { Gender }\end{array}$ & $61(10.0 \%)$ & $551(90.0 \%)$ & \\
Female & $29(12.0 \%)$ & $271(88.0 \%)$ & 0.154 \\
$\quad$ Male & $29(8.5 \%)$ & $311(91.5 \%)$ & \\
Ethnic & & & \\
Malay & $42(10.4 \%)$ & $361(89.6 \%)$ & 0.605 \\
Chinese & $19(9.2 \%)$ & $188(90.8 \%)$ & \\
Indian & $5(14.7 \%)$ & $29(85.3 \%)$ & \\
Healthcare Facilities Used & & \\
Hospital & $13(6.7 \%)$ & $180(93.3 \%)$ & 0.059 \\
Health clinic & $53(11.6 \%)$ & $402(88.4 \%)$ & \\
District & $39(9.4 \%)$ & $376(90.6 \%)$ & 0.376 \\
Kota Setar & $27(11.6 \%)$ & $206(88.4 \%)$ & \\
Kuala Muda & & & \\
\hline
\end{tabular}

${ }^{a}$ Chi square test for independence
Table 4. Detective rate of iFOBT, Colonoscopic Compliance and Colonoscopic Findings in Both Districts in Malaysia

\begin{tabular}{|c|c|}
\hline Screening Methods & Frequency $(\%)$ \\
\hline \multicolumn{2}{|l|}{ iFOBT Screening } \\
\hline Positive & $72(9.6 \%)$ \\
\hline Negative & $576(76.8 \%)$ \\
\hline Defaulter & $102(13.6 \%)$ \\
\hline Total & $750(100.0 \%)$ \\
\hline \multicolumn{2}{|l|}{ Colonoscopy compliance } \\
\hline Compliant & $49(68.1 \%)$ \\
\hline Defaulted & $23(31.9 \%)$ \\
\hline Total & $72(100.0 \%)$ \\
\hline \multicolumn{2}{|l|}{ Colonoscopy } \\
\hline Positive & $26(53.1 \%)$ \\
\hline Negative & $23(46.9 \%)$ \\
\hline Total & $49(100.0 \%)$ \\
\hline \multicolumn{2}{|l|}{ Colonoscopic findings } \\
\hline Hemorrhoid & $9(34.6 \%)$ \\
\hline Tubular adenoma & $7(26.9 \%)$ \\
\hline Acute colitis & $3(11.5 \%)$ \\
\hline Rectal ulcer & $3(11.5 \%)$ \\
\hline Diverticulitis & $2(7.7 \%)$ \\
\hline Adenocarcinoma & $1(3.9 \%)$ \\
\hline Serrated adenoma & $1(3.9 \%)$ \\
\hline Total & $26(100 \%)$ \\
\hline
\end{tabular}

findings in the colonoscopy. The most common positive finding was hemorrhoid in the colonoscopy. Tubular adenoma was the second most common finding while there was an adenocarcinoma detected at stage IIIC. Detection rate for neoplasia and carcinoma in the study was $1.2 \%$ while detection rate for carcinoma alone was $0.13 \%$.

\section{Discussion}

The response rate of our patients in colorectal cancer screening is comparable to a few national programs based on FOBT screening in Scotland (Steele et al., 2010), England (Moss et al., 2011; Logan et al., 2012), and France (Leuraud et al., 2013). Our response rate for FOBT was actually higher as we only included two districts for evaluation of colorectal cancer screening. On the other hand, the former studies were using national level database. The studies in Scotland (Steele et al., 2010), England (Moss et al., 2011; Logan et al., 2012) and France (Leuraud et al., 2013) found out that female was higher in uptake of colorectal cancer screening, however, there was no significant different between both genders in the current study. The difference could be attributed to inadequate sample size in this study to detect the significant difference.

In the current study, we found out that Indian ethnicity was 3.5 times more likely to default colorectal cancer screening as compared to Malay, while no difference was detected between Malay and Chinese ethnicity. Although interesting, this body of evidence must be treated with caution as the data used in the current study were not population-based. On top of that, most of the former studies did not explore into the difference between ethnicities, thus, there is limited comparison on this evidence. In 
addition, we also found that patients from Kuala Muda were 27.5 times more likely to default as compared to patients from Kota Setar district. This geographical difference was also highlighted in England (Moss et al., 2011; Logan et al., 2012) whereby it was attributed to socio-demographic factors such as affluence, deprivation and composition of the community (Moss et al., 2011). As for the two districts in the study, the urbanization is very much similar and composition of community was also alike, though, health seeking behavior and perception on colorectal cancer screening should be explored in the coming years to explain the difference.

Overall iFOBT positivity at $9.6 \%$ is an encouraging finding but lower compared to FOBT positivity rate (18.8\%) in Tokyo (Oono et al., 2010). Paradoxically, our iFOBT positivity rate is higher than most of the other national screening program in Scotland, England and France (Steele et al., 2010; Moss et al., 2011; Logan et al., 2012). On top of that, Nottingham trial had $2.1 \%$ (first invitation) and $2.7 \%$ (reinvitation) positive FOBT in their first round screening (Hardcastle et al., 1996). The difference between our study and the former studies could be due to number of enrolment whereby the former had population-based involvement. On top of that, utilization of either immunochemical or guaiac FOBT could have attributed to difference in positivity rate between all of the studies aforementioned. Immunochemical FOBT was found to be more superior than guaiac FOBT (Castiglione et al., 1996; Launoy et al., 2005). The aforementioned studies in England (Moss et al., 2011; Logan et al., 2012), Scotland (Steele et al., 2010) and France (Leuraud et al., 2013) were utilizing guaiac as compared to immunochemical FOBT was used in Japan (Oono et al., 2010) and our study.

FOBT positivity was also found to be associated with gender, screening rank, deprivation, and composition of the district in the previous studies; however, we found no association in this study. Not surprisingly, a study involving a larger number of subjects might be required to determine the association for our setting. As for colonoscopy compliance, the compliance was evidently higher in England (Moss et al., 2011), Scotland (Steele et al., 2010) and France (Leuraud et al., 2013). The obvious difference in colonoscopy compliance could be contributed by perception and acceptance of colonoscopy in the community. Another interesting finding regarding higher colonoscopy compliance in second iFOBT screening (Ferrat et al., 2013) was also observed in our study, which could be due to repeated encounter and counseling by healthcare practitioners.

Detection rate of neoplasia and carcinoma as well as detection rate of carcinoma alone in this study was lower than England, Scotland and France (Steele et al., 2010, Moss et al., 2011; Leuraud et al., 2013). In addition, the global carcinoma detection rate was higher at $1.9 \%$ (Leuraud et al.,2013). The low detection rate in our setting could be due to low colonoscopy uptake among those with positive iFOBT. Thus, further effort should be taken to improve colonoscopy compliance and this could directly increase the detection rate of neoplasia and carcinoma. In addition, positive iFOBT without any colonoscopy will be an incomplete screening of colorectal carcinoma. Cost effectiveness analysis also proved that combination of FOBT and sigmoidoscopy or colonoscopy is the most effective strategy (Frazier et al., 2000).

This study merely covers only two districts; thus, the result is not completely representative of the whole territory. Furthermore, this evaluation has presented some limitations in data collection for the screening program. For instance, a few missing data for iFOBT collection in both districts could have slightly affected its detection rate. Other than its limitation, this study also has its strength whereby the evaluation was conducted in a multiracial setting whereby this was rarely reported in the previous studies. To our knowledge, this is also the very first study evaluating the outcome of colorectal cancer screening in Malaysia. As a result, it will serve as a significant piece of information for the planning of colorectal cancer screening program in this country.

In summary, the colorectal cancer screening is a crucial cancer screening program in our effort to reduce all cause mortality by colorectal cancer. The detection rate for neoplasia and carcinoma is still suboptimal in our setting and further strengthening of the program is very much needed to achieve a favaourable outcome. In our effort to improve the screening program, primary healthcare facilities are particularly important and their ability to conduct the screening program should be well addressed and further strengthened.

\section{Acknowledgements}

We would like to express our gratitude to the Director General of Health, Malaysia for supporting this publication. In addition, we would like to thank to all parties who are directly or indirectly involved in the process of this study.

\section{References}

Cairns SR, Scholefield J (2002). Guidelines for colorectal cancer screening in high risk groups. Gut, 51, 1-2.

Cairns SR, Scholefield JH, Steele RJ, et al (2010). Guidelines for colorectal cancer screening and surveillance in moderate and high risk groups. Gut, 59, 666-89.

Castiglione G, Zappa M, Grazzini G, et al (1996). Immunochemical vs guaiac faecal occult blood tests in a population-based screening programme for colorectal cancer. British J Cancer, 74, 141.

Compton CC, Fielding LP, Burgart LJ, et al (2000). Prognostic factors in colorectal cancer. Arch Pathol Lab Med, 124, 979-94.

Ferrat E, Le Breton J, Veerabudun K, et al (2013). Colorectal cancer screening: factors associated with colonoscopy after a positive faecal occult blood test. Br J Cancer, 109, 1437-44.

Frazier AL, Colditz GA, Fuchs CS, et al (2000). Costeffectiveness of screening for colorectal cancer in the general population. JAMA, 284, 1954-61.

Hardcastle JD, Chamberlain JO, Robinson MH, et al (1996). Randomised controlled trial of faecal-occult-blood screening for colorectal cancer. Lancet, 348, 1472-7.

Hewitson P, Glasziou P, Watson E, et al (2008). Cochrane systematic review of colorectal cancer screening using the fecal occult blood test (hemoccult): an update. Am J 
Gastroenterol 103, 1541-9.

Kronborg O, Fenger C, Olsen J, et al (1996). Randomised study of screening for colorectal cancer with faecal-occult-blood test. Lancet, 348, 1467-71.

Launoy GD, Bertrand HJ, Berchi C, et al (2005). Evaluation of an immunochemical fecal occult blood test with automated reading in screening for colorectal cancer in a general average-risk population. Int J Cancer, 115, 493-6.

Leuraud K, Jezewski-Serra D, Viguier J, et al (2013). Colorectal cancer screening by guaiac faecal occult blood test in France: Evaluation of the programme two years after launching. Cancer Epidemiol, 37, 959-67.

Logan RF, Patnick J, Nickerson C, et al (2012). Outcomes of the bowel cancer screening programme (BCSP) in England after the first 1 million tests. Gut, 61, 1439-46.

Meester RG, Doubeni CA, Lansdorp-Vogelaar I, et al (2015). Colorectal cancer deaths attributable to nonuse of screening in the United States. Ann Epidemiol, 25, 208-13.

Ministry of Health, Malaysia (2007). National cancer registry report: malaysia cancer statistics - data and Figure.

Moss S, Campbell C, Melia J, et al (2011). Performance measures in three rounds of the English bowel cancer screening pilot. Gut, 2010, 236430.

O’Connell JB, Maggard MA, Ko CY (2004). Colon cancer survival rates with the new american joint committee on cancer sixth edition staging. J Natl Cancer Inst, 96, 1420-5.

Oono Y, Iriguchi Y, Doi Y, et al (2010). A retrospective study of immunochemical fecal occult blood testing for colorectal cancer detection. Clinica Chimica Acta, 411, 802-5.

Steele R, Kostourou I, McClements P, et al (2010). Effect of gender, age and deprivation on key performance indicators in a FOBT-based colorectal screening programme. J Med Screen, 17, 68-74.

Winawer S, Fletcher R, Rex D, et al (2003). Colorectal cancer screening and surveillance: clinical guidelines and rationaleupdate based on new evidence. Gastroenterol, 124, 544-60. 